\title{
Effect of natural fibres on the mechanical properties of thermoplastic starch**
}

\author{
Tomasz Oniszczuk ${ }^{1 *}$, Agnieszka Wójtowicz ${ }^{1}$, Leszek Mościcki ${ }^{1}$, Marcin Mitrus ${ }^{1}$, Karol Kupryaniuk ${ }^{1}$, \\ Andrzej Kusz', and Grzegorz Bartnik ${ }^{3}$ \\ ${ }^{1}$ Department of Food Process Engineering, University of Life Sciences, Doświadczalna 44, 20-236 Lublin, Poland \\ ${ }^{2}$ Department of Technology Fundamentals, University of Life Sciences, Doświadczalna 50A, 20-280 Lublin, Poland \\ ${ }^{3}$ Department of Mechanical Engineering and Automation, University of Life Sciences, Głęboka 28, 20-612 Lublin, Poland
}

Received July 9, 2015; accepted February 1, 2016

\begin{abstract}
A b s t r a c t. This paper presents the results covering the mechanical properties of thermoplastic potato starch granules with flax, cellulose fibre, and pine bark addition. A modified single screw extrusion-cooker TS-45 with L/D = 18 and an additional cooling section of the barrel was used as the processing unit. The establishment influence of the fibre addition, as well as the extrusion-cooker screw speed, on the mechanical properties of the thermoplastic starch granules was the main objective of the investigation. The maximum force during compression to $50 \%$ of the sample diameter, elastic modulus, and compression strength were evaluated. Significant differences were noted depending on the amount of fibre used, while only an insignificant influence of screw speed on the mechanical properties of the granulate was reported. An increased amount of fibres lowered the maximum force as well as the elastic modulus and compression strength of the thermoplastic starch granulates.

K e y w o r d s: thermoplastic starch, natural fibre, mechanical properties
\end{abstract}

\section{INTRODUCTION}

One of the biggest challenges of modern polymer technology is to find replacements for rapidly decreasing, non-renewable, natural resources and to solve the already burdensome problems of plastic waste management (Matkó et al., 2005). The increasing amount of produced waste is becoming a challenge for the natural environment. Most plastic waste is resistant to degradation due to the composition of polymers, which decompose in the environment over a very long time. In recent years, some large-scale studies have been undertaken looking at how to increase the share of starch in starch-plastic composites to the maximum possible level and respond to the deficiencies of

*Corresponding author e-mail: tomasz.oniszczuk@up.lublin.pl

**This work was supported by the Ministry of Science and Higher Education as a research project No. NN313275738, 2010-2012. existing technologies. Due to the increasing environmental consciousness and the initiatives of legislative authorities, nowadays, the use of biodegradable composite materials is becoming a solution to some environmental problems. There has been a growth in the production of biodegradable materials used across the industry. These products are growing in popularity in many sectors, mostly in the packaging industry (Mościcki and Janssen, 2009). Thermoplastic starch (TPS) can be used as a stand-alone packaging material or as an additive that improves the degradation of plastics. Its application is possibly due to the relatively short time of degradation to $\mathrm{CO}_{2}$ and water. Biocomposites that are enriched with starch are mainly used in making film, containers, and in the production of foams used for the filling of empty spaces inside packaging and parcels (Mitrus, 2012; Spychaj et al., 2008). Machinery and equipment used by plastic manufacturers can be applied to the manufacturing of TPS-based products.

Thermoplastic starch can be obtained by treatment with temperature and pressure in the presence of a plasticizer, like water, glycerol, or sorbitol, for example, with the extrusion-cooking technique (Mościcki et al., 2012; Stepto, 2003). The issue of using starch of different origin (mostly maize, wheat, potato, tapioca) for the production of TPS biodegradable packaging materials is discussed in numerous scientific papers (Chen and Evans, 2005; Cyras et al., 2008; Huang et al., 2004, 2005; Souza and Andrade, 2002). This type of biodegradable products may be complementary to alternative plastics; however, they do not have a wide application due to certain defects ie brittleness, retrogradation, and hygroscopic properties (Averous and Boquillon,

(C) 2016 Institute of Agrophysics, Polish Academy of Sciences 
2004; Mitrus and Mościcki, 2009; Ray et al., 2007; Thomas and Atwell, 1997). The mechanical properties of TPS-based materials are worse than those of conventional plastics. In order to improve their physical properties, elasticity and material strength of obtained products, various fibres should be added to raw material blends. The main focus for now seems to be the use of biodegradable, renewable raw materials as a matrix material with biofibres as reinforcement and combination thereof into 'eco-friendly' and environmentally safe final products (Ray et al., 2007). For some years now, fibre-reinforced polymer matrix composites have been used in diverse fields, like sporting goods, cars, microlight aircrafts, electronic components, artificial joints, household articles, or structural components. Since both components are biodegradable, the composite as an integral part is also expected to be biodegradable (Averous and Boquillon, 2004).

Biodegradable composites consist of biodegradable polymers as a matrix material and biodegradable fibres, usually biofibres (Suprakas and Mosoto, 2005). Jute, hemp, lignocellulose, flax fibre, coir, cotton, and oriental plant fibres seem to be the most commonly applied materials (Cyras et al., 2008; Matkó et al., 2005). Various fibres should be added to the raw material blends in the amount ranging from 1 to even $50 \%$, depending on the type of additives used. The main disadvantage of these fibres is that their mechanical properties depend on several factors, such as moisture content, cultivation area, and processing methods. Their thermal stability is also notably poor (Ray et al., 2007). The optimization and industrial production of biocomposites with natural fibre reinforcement is limited due to these variations. The combinations of these natural fibres with biodegradable matrices offer the opportunity to achieve the desired properties of the final product.

The aim of this work was to study the influence of addition of different types of fibre on selected mechanical properties of plasticized starch processed with the extrusion-cooking technique.

\section{MATERIALS AND METHODS}

Potato starch of the Superior Standard-F type, produced by PEPEES S.A. (Łomża, Poland), mixed with $20 \%$ of glycerol of 99\% purity (Odczynniki Chemiczne, Lublin, Poland) was used as the basic raw material. The following additives: cellulose fibre of vivapur type 102 (JRS GmbH, Germany) (particle size $5010^{-6}-16010^{-6} \mathrm{~m}$, bulk density $280-330 \mathrm{~kg} \mathrm{~m}^{-3}$, humidity $3-5 \%$ ), flax fibre (particle size $310^{-3}-510^{-3} \mathrm{~m}$, bulk density $145-150 \mathrm{~kg} \mathrm{~m}^{-3}$, humidity $5-7 \%$ ), and pine bark (from Polish agricultural producers) (particle size $5010^{-6}-18010^{-6} \mathrm{~m}$, bulk density $120-250$ $\mathrm{kg} \mathrm{m}^{-3}$, humidity 3-8\%) were applied. The amount of fibre in the prepared blends was set to 10,20 , and $30 \%$ of the sample mass; samples without additives were prepared for comparison. Potato starch (16\% of the moisture con- tent) and the additives were mixed in a laboratory ribbon mixer for $20 \mathrm{~min}$. Next, the blends of different composition were stored for $24 \mathrm{~h}$ in plastic bags before the tests. The prepared samples were again mixed for 10 min prior to extrusion-cooking, which guaranteed a loose structure of the compounds.

The study was performed using a modified single screw extrusion-cooker type TS-45 (Polish design) with $\mathrm{L} / \mathrm{D}=18 / 1$, equipped with an additional cooling section of the barrel and a forming die with a $3 \mathrm{~mm}$ hole diameter. Granulates were produced using an extruder screw speed of 60,80 , and 100 r.p.m. The extrusion-cooking process temperature was set in the range from 80 to $120^{\circ} \mathrm{C}$ and maintained appropriately, adjusting the flow intensity of the cooling liquid. The processing temperature was measured by thermocouples installed along the barrel; the results were recorded. The rotational speed of the screw was monitored by the electronic tachometer DM-223AR Wireless.

The starch/fibre composite granulates were subjected to compression tests in accordance with Polish Standard PN-83/C-89031 (1983) and self-modified to measure their mechanical strength and the elastic modulus values of the composites. For each set, five samples were tested and the mean value was reported. A universal testing machine Zwick-Roell type BDO-FBO 0.5TH (Ulm, Germany) with the working head of $500 \mathrm{~N}$ was used in the experiments. Single granules were placed on the testing table and compressed between the flat plates with a test speed of $50 \mathrm{~mm} \cdot \mathrm{min}^{-1}$. The initial force was set to $1 \mathrm{~N}$, the compression plate displacement was $50 \%$ of the granulate diameter measure, for each sample. The results were calculated with the testXpert 10.11 software for the elastic modulus and compression strength values. The elastic modulus was estimated by tangent, in a range from $5 \mathrm{~N}$ of compression force to the end of the experiment as a degree of strain and a function of stress. Compression strength was defined as the amount of stress required to deform the material in the defined range and was calculated by dividing the maximum force by the original cross-sectional area of granulates subjected to the compression test (Smal, 2009).

The results were analysed using the statistical software Statistica 6.0, examining the relationships between the amounts of additives used and the screw rpm applied. The results were investigated by means of the response surface regression analysis. Correlation coefficients were evaluated and an analysis of variance was conducted at a confidence level of $95 \%(p=0.05)$; the significance of differences was assessed in a Duncan range test.

\section{RESULTS AND DISCUSSION}

The characteristics of granulates subjected to compression tests may be useful for their applications in further processing, for example, injection moulding or pressing, and may provide information about the mechanical 
properties and the ability to produce new kinds of stiff forms of packaging materials, such as plates or boxes. The forces required to compress show resistance to deformation; therefore, it may be concluded than the lower forces applied during the granulate compression tests facilitated easier formation of the final product shape.

Figure 1 shows examples of the curves of compression tests of potato starch granulate, with and without flax addition, processed at a 60 r.p.m. screw speed. For starch granulates without additives, high compression forces were observed during the deformation of granulates, up to $50 \%$ of their diameter. The values around $400 \mathrm{~N}$ were reached, which suggests high resistance to compression. Small differences were observed for the potato starch granulates processed at the different screw speed values. A low impact of the extrusion conditions on the resistance of the samples to compression was observed.

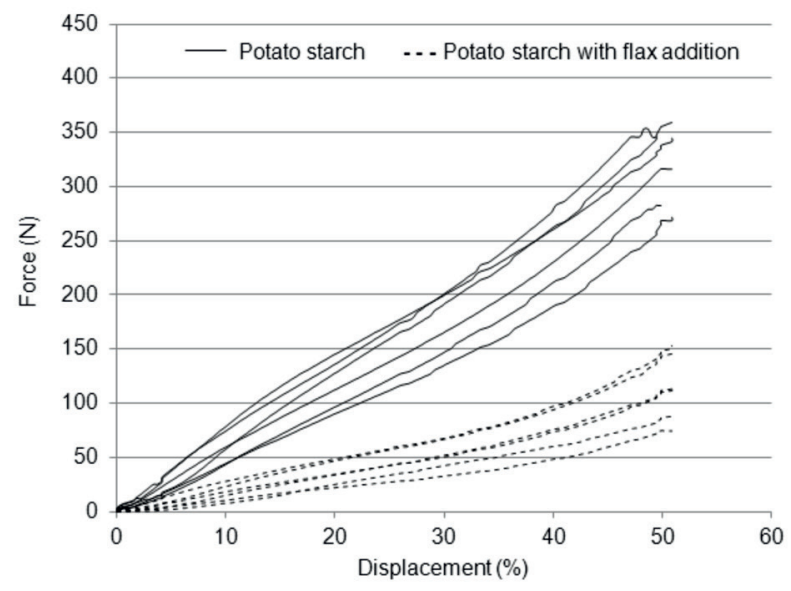

Fig. 1. Exemplary curves for compression tests of potato starch granulates with and without $30 \%$ of flax addition processed at 60 r.p.m. screw speed.

The presented results exhibited decreasing resistance to compression when the fibres were added, which may be the result of granulates losing their internal structure depending on the incompatibility of starch and fibrous materials. Some enzymatic or chemical modifications of the fibre could be applied to improve the compatibility of these components (Cyras et al., 2008; Ray et al., 2007; Thomas and Atwell, 1997; Zhang and Sun, 2004). These factors were also reported by other researchers. Extrusion-cooking may also be some kind of thermal modification processing as it changes the chemical structure of starch chains, viscosity, solubility, and the microstructure of extruded materials (Camire et al., 1990; Hagenimana et al., 2006; Souza and Andrade, 2002).

The assessment of the compression tests allows identification of some more mechanical properties of the tested materials ie elasticity, strain, or stress. Potato starch granulates revealed the highest values of the elastic modulus varying from $94.5 \mathrm{MPa}$ for granulates processed at the
60 r.p.m. screw speed to $65 \mathrm{MPa}$ when 100 r.p.m. was applied during processing. The lowest values were reported for potato starch granulates processed at 80 r.p.m.; the samples extruded in these conditions showed lower elasticity than those mentioned above. These high values result from the rapidly increased compression forces observed in Fig. 1 and the shape of the obtained curves. The use of tangent in the proposed range for the determination of the elastic modulus showed a precise representation of this parameter. Enhanced mechanical properties were also observed in the case of matrices containing higher amounts of starch (Zhang and Sun, 2004). The properties were lower in the clay-modified matrices.

The values of the elastic modulus of the tested granulate varied with the changing screw speed of the extruder during processing as well as the type of fibre used and its amount. Figure 2a presents the elastic modulus values for the different amounts of pine bark-reinforced granulate processed at various screw speeds during the compression test.

A major influence was observed of the pine bark content on the reduction of the elastic modulus when compared to samples processed without additives. At the level of $10 \%$ additive, the elastic modulus values decreased at screw speeds applied from $12 \mathrm{MPa}$ for 60 r.p.m. to $7 \mathrm{MPa}$ for 100 r.p.m. The same trend was noted for granulates with $30 \%$ of pine bark addition and the values reached from 11.5 to $7.2 \mathrm{MPa}$. Some small differences, around $1 \mathrm{~N}$, were observed between the results for samples reinforced with $20 \%$ of pine bark processed at various screw speeds (9.2-10.4 MPa). For these samples, a strong lowering impact of the screw speed on the elastic modulus was observed (Table 1).

More than two-fold lower results were reported during the compression tests of granulates with the addition of flax fibre. The results presented in Fig. $2 \mathrm{~b}$ also showed an opposite trend than the one observed for granulates with pine bark. In these samples, the elastic modulus values evaluated with the compression test were higher at the higher screw speeds applied during granulate processing.

Samples with an addition of $10 \%$ of flax fibre showed the results for the elastic modulus ranging from 5.7 to 9.7 $\mathrm{MPa}$ when the screw speed increased from 60 to 100 r.p.m., accordingly. For granulates reinforced with $20 \%$ of flax fibre, the elastic modulus was from $4.5 \mathrm{t}$ 7.5 $\mathrm{MPa}$, and the increase in the level of an additive resulted in lower modulus values from 2.8 to $3.9 \mathrm{MPa}$ when a higher screw speed was used during extrusioncooking. This shows that the addition of flax fibre formed a less elastic structure of granulates. Only in this type of fibre, an increase in screw speed yielded higher values of elasticity of reinforced granulates (Table 1).

The highest elastic modulus values were reported when cellulose fibres were applied for potato starch reinforcement. An addition of 10 and $20 \%$ of cellulose fibres resulted in an elastic modulus of 22.5 and $24.2 \mathrm{MPa}$, respectively, 
a

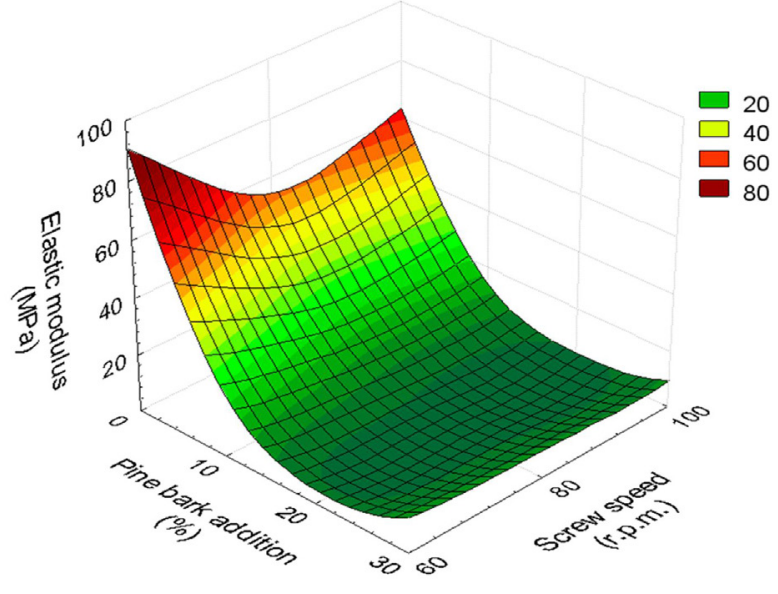

b

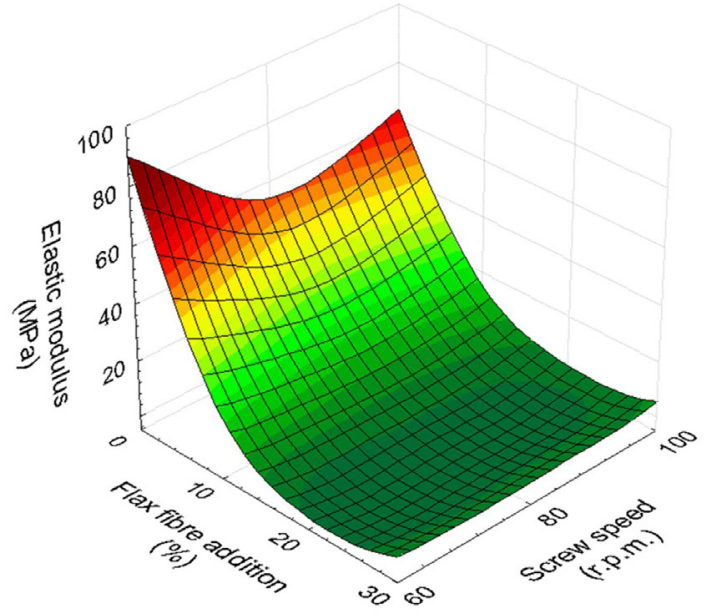

c

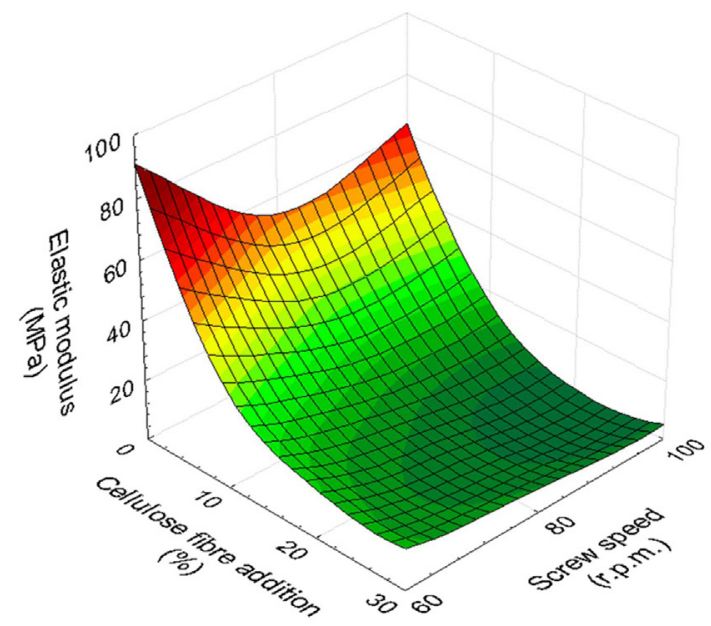

Fig. 2. Elastic modulus values for a different amount of: a - pine bark-reinforced, b - flax fibre-reinforced, c - cellulose fibrereinforced granulate processed at various screw speeds during compression test. during the compression of samples processed at 60 r.p.m.. Increasing the screw speed to 80 and 100 r.p.m. during granulate processing reduced the elastic modulus values two fold. An elastic modulus of 13.5 and $11.3 \mathrm{MPa}$ was estimated for samples with $10 \%$ of cellulose fibre processed at 80 and 100 r.p.m., respectively (Fig. 2c). An addition of 20 and $30 \%$ of cellulose fibre to the granulate recipe yielded an elastic modulus ranging from 12.6 to $4.5 \mathrm{MPa}$ when the higher screw speed was applied during extrusioncooking. In addition, for these samples, high values of correlation coefficients $(-0.942$ to -0.999$)$ were calculated depending on the increase in the amount of cellulose fibre in the granulate composition at the level of significance of 0.0012 (Tables 1 and 3).

Some insignificant differences between the mean results were recorded depending on the screw speed changes (Table 2), which suggests slight changes between the tested samples, yet the correlation coefficients were around -0.83 . Therefore, the trend to reduction of the elastic modulus while increasing the screw speed during processing is quite strong.

The compression strength of the tested starch-based granulates generally declined along with the increasing amount of the fibre addition, especially compared with potato starch granulates without additives. For these starchy products, the values of compression strength in the compression test decreased with an increased screw speed applied during granulate processing, that is, from 19.4 to 13.7 MPa at 60 and 100 r.p.m., respectively. This showed that the higher screw speed is likely to lead to the formation of a more porous structure with less resistance to compression. This is in accordance with the available knowledge about the extrusion-cooking process of starchy materials (Camire et al., 1990; Mościcki and Janssen, 2009).

The results of compression strength during the test performed for granulates reinforced with the addition of pine bark are presented in Fig. 3a. A slight trend to lower the compression strength of granulates depending on the increase in the amount of an additive was observed and confirmed by the statistics shown in Table 2 (the correlation coefficients varied from -0.63 to -0.83 at various screw speeds during the processing of the granulate) at a significance level of 0.0002 . The influence of different screw speeds is negligible (Table 1) with regard to the parameter values with some insignificant differences in mean results (Table 4). The introduction of a small amount of pine bark to the granulate recipe resulted in a reduction of mechanical resistance, compared with potato starch granulates. A further increase in the modifier content caused a decrease in the compression strength values.

A major decrease, more than double, was observed in the compression strength when flax fibre additives were added to starch. The compression strength values of granulates reinforced by flax fibres were low and varied from $8.3 \mathrm{MPa}$ at $10 \%$ of the additive, and slightly grew with the 
T a b l e 1. Correlation coefficients of the mechanical properties of fibre-reinforced granulate depend on the screw speed for samples with the different type and amount of fibres

\begin{tabular}{cccccccc}
\hline \multirow{2}{*}{$\begin{array}{c}\text { Additive level } \\
(\%)\end{array}$} & \multicolumn{3}{c}{ Elastic modulus (MPa) } & & \multicolumn{3}{c}{ Compression strength (MPa) } \\
\cline { 2 - 3 } & Pine bark & Flax fibre & Cellulose fibre & & Pine bark & Flax fibre & Cellulose fibre \\
\hline 0 & -0.634 & -0.634 & -0.634 & & -0.937 & -0.937 & -0.937 \\
10 & -0.994 & 0.988 & -0.942 & & -0.495 & 0.700 & -0.694 \\
20 & -0.933 & 0.326 & -0.994 & & -0.529 & 0.619 & -0.792 \\
30 & -0.999 & 0.675 & -0.999 & & -0.565 & -0.943 & -0.971 \\
\hline
\end{tabular}

T a b l e 2. Correlation coefficients of the mechanical properties of fibre-reinforced granulates depending on the various level of additive at the same screw speed applied during processing

\begin{tabular}{cccccccc}
\hline \multirow{2}{*}{$\begin{array}{c}\text { Screw speed } \\
\text { (r.p.m.) }\end{array}$} & \multicolumn{3}{c}{ Elastic modulus (MPa) } & & \multicolumn{3}{c}{ Compression strength (MPa) } \\
\cline { 2 - 3 } \cline { 7 - 8 } & Pine bark & Flax fibre & Cellulose fibre & & Pine bark & Flax fibre & Cellulose fibre \\
\hline 60 & -0.777 & -0.789 & -0.837 & & -0.830 & -0.700 & -0.834 \\
80 & -0.783 & -0.834 & -0.832 & & -0.631 & -0.917 & -0.977 \\
100 & -0.772 & -0.823 & -0.830 & & -0.784 & -0.910 & -0.909 \\
\hline
\end{tabular}

T a b l e 3. Analysis of variance results of the influence of an additive amount on the tested mechanical properties

\begin{tabular}{|c|c|c|c|c|c|c|c|c|c|}
\hline \multirow{2}{*}{ Parameter } & \multirow{2}{*}{ Additive } & \multicolumn{3}{|c|}{ Effect } & \multicolumn{3}{|c|}{ Error } & \multirow{2}{*}{$\mathrm{F}$} & \multirow{2}{*}{$\mathrm{p}$} \\
\hline & & SS & $\mathrm{df}$ & MS & SS & $\mathrm{df}$ & MS & & \\
\hline \multirow{3}{*}{$\begin{array}{l}\text { Elastic } \\
\text { modulus }\end{array}$} & Pine bark & 8221.2 & 3 & 2740.40 & 1075.72 & 8 & 134.46 & 20.380 & 0.0004 \\
\hline & Flax fibre & 9356.2 & 3 & 3118.75 & 1066.49 & 8 & 133.31 & 23.394 & 0.0002 \\
\hline & $\begin{array}{l}\text { Cellulose } \\
\text { fibre }\end{array}$ & 7532.7 & 3 & 2510.90 & 1353.14 & 8 & 169.14 & 14.844 & 0.0012 \\
\hline \multirow{3}{*}{$\begin{array}{l}\text { Compression } \\
\text { strength }\end{array}$} & Pine bark & 288.02 & 3 & 96.01 & 32.14 & 8 & 4.01 & 23.892 & 0.0002 \\
\hline & Flax fibre & 352.24 & 3 & 117.41 & 50.65 & 8 & 6.33 & 18.542 & 0.0005 \\
\hline & $\begin{array}{l}\text { Cellulose } \\
\text { fibre }\end{array}$ & 236.97 & 3 & 78.99 & 53.88 & 8 & 6.73 & 11.727 & 0.0026 \\
\hline
\end{tabular}

$\mathrm{SS}$ - sum of squares, MS - mean squares.

increasing screw speed (Table 1) to 2.2 MPa for the highest flax fibre content with a lowering trend when a higher screw speed was applied. The results of the compression strength of flax fibre-reinforced granulates are presented in Fig. 3b. The compression values were higher with the higher screw speed during processing for samples with 10 and $20 \%$ of flax addition, but when $30 \%$ was applied an opposite effect was observed with an increased screw speed on granulate compression. The structure of samples with 10 and $20 \%$ of flax fibres was more compact than that observed for granulates with the $30 \%$ additive, which had more porous and loose insight structure, and the increased screw speed contributed to formation of less compres- sible samples. For these results, a strong effect of the fibre quantity was observed at all screw speeds used in the experiment (Table 2) at a significance of 0.0005 (Table 3), and an insignificant effect of the screw speed applied during the processing was reported (Table 4). This reveals a strong impact of this type of fibre on the mechanical properties of the tested granulates.

Figure $3 \mathrm{c}$ shows the results of the compression strength of granulates with an addition of cellulose fibre. The samples showed higher elastic modulus values; also in this case, the results of resistance to compression were higher than those observed for pine bark or flax fibres. 
T a b l e 4. Analysis of variance results of the influence of screw speed range on the tested mechanical properties

\begin{tabular}{|c|c|c|c|c|c|c|c|c|c|}
\hline \multirow{2}{*}{ Parameter } & \multirow{2}{*}{ Additive } & \multicolumn{3}{|c|}{ Effect } & \multicolumn{3}{|c|}{ Error } & \multirow{2}{*}{$\mathrm{F}$} & \multirow{2}{*}{$\mathrm{p}$} \\
\hline & & SS & $\mathrm{df}$ & MS & SS & $\mathrm{df}$ & MS & & \\
\hline \multirow{3}{*}{$\begin{array}{l}\text { Elastic } \\
\text { modulus }\end{array}$} & Pine bark & 350.39 & 2 & 175.19 & 8946.54 & 9 & 994.06 & 0.176 & 0.841 \\
\hline & Flax fibre & 254.25 & 2 & 127.12 & 10168.52 & 9 & 1129.83 & 0.112 & 0.894 \\
\hline & $\begin{array}{l}\text { Cellulose } \\
\text { fibre }\end{array}$ & 791.09 & 2 & 395.54 & 8094.77 & 9 & 899.41 & 0.439 & 0.657 \\
\hline \multirow{3}{*}{$\begin{array}{l}\text { Compression } \\
\text { strength }\end{array}$} & Pine bark & 13.65 & 2 & 6.82 & 306.51 & 9 & 34.05 & 0.200 & 0.821 \\
\hline & Flax fibre & 1.05 & 2 & 0.52 & 401.85 & 9 & 44.65 & 0.011 & 0.988 \\
\hline & $\begin{array}{l}\text { Cellulose } \\
\text { fibre }\end{array}$ & 45.21 & 2 & 22.60 & 245.65 & 9 & 27.29 & 0.828 & 0.467 \\
\hline
\end{tabular}

Explanations as in Table 3.

Thermoplastic, starch-based granulates reinforced with cellulose fibres, obtained at various screw rotational speeds are slightly different, depending on the structure of cellulose and its longer fibres in the structure, compared with pine bark. This may be the cause of the higher values in the mechanical properties of granulates with the cellulose fibre addition. The values of compression strength varied from $18 \mathrm{MPa}$ for $10 \%$ of additive used to $7.3 \mathrm{MPa}$ at $30 \%$ of granulate reinforcement. The trend in the screw speed changes showed reduction of the tested parameter, depending on both the screw speed applied and the amount of cellulose fibre (Table 1 and 2), with a more significant effect of the increased additive level (Table 3 ). This confirms a higher resistance to compression of the material in question, compared to the others used in the experiments. The differences in the evaluated data may be attributed to the method of preparation of the starch-based composites. Nanocomposites with starch and functional additives exhibited a remarkable improvement in the mechanical properties such as Young modulus and tensile stress (Chen and Evans, 2005; Cyras et al., 2008). Ray et al. (2007) reported that jute fabric reinforcement effectively increased the mechanical properties of the starch-based matrix and such composites. Therefore, we can find eco-friendly applications in new fields. The improvement of the mechanical properties of thermoplastic starch has been investigated by many researchers in recent years. Mendes et al. (2016) developed the effect of incorporating thermoplastic chitosan (TPC) in a thermoplastic cornstarch (TPS) matrix on the mechanical properties of this material. The results show that it was possible to produce successfully corn starchchitosan blends by extrusion with high dispersion of the thermoplastic. Chitosan in thermoplastic corn starch was observed by scanning electron microscopy analyses. The addition of 5 and $10 \mathrm{wt} . \%$ TPC served as a plasticizer to the TPS matrix, increasing the elongation at break (from 56 to $35 \%$ ) and decreasing tensile strength and elastic modulus.
The objective of the work conducted by Dang and Yoksan (Dang and Yoksan, 2015) was to improve the properties of TPS-based materials by incorporating plasticized chitosan (CTS). TPS/CTS-based materials were prepared using a twin-screw extruder and then converted into a film by blown film extrusion. The findings showed that chitosan could establish a hydrogen bond interaction with starch, resulting in positive effects on film properties. The addition of $0.37-1.45 \%$ of chitosan improved strength (tensile strength increased $~ 8-97 \%$ ) and stiffness (Young modulus increased $\sim 40-154 \%$ ). However, the extensibility of TPS film decreased (the elongation at break decreased $~ 5-73 \%$ ) when chitosan was incorporated.

Hietala, Mathew, and Oksman (Hietala et al., 2013) investigated the mechanical properties of thermoplastic starch nanocomposites enriched with cellulose nanofibre (CNF) gels. Nanocomposites containing 0, 5, 10, 15, and 20 wt. $\%$ of CNF were examined. The cellulose nanofibre gel (containing $12 \mathrm{wt} . \%$ of water) was mixed with starch powder and fed to the extruder as powder, performing gelatinization of starch as well as mixing of CNF in one step. The results showed that the tensile strength and modulus of the starch matrix were improved with the addition CNF. The tensile modulus increased linearly with the increasing nanofibre content. However, the strength properties were the highest for the samples with addition $10 \%$ of CNF. This follows from the fact that, for the material with 15 and 20 wt. $\%$ of CNF, cellulose nanofibres can form aggregates in the composite.

Results of studies conducted by Canché-Escamilla et al. (2011) demonstrated that the mechanical properties of thermoplastic starch could be modified by the use of grafted polymers. The use of rigid (PMMA) and rubbery polymers (PBA) increased the flexibility of thermoplastic grafted starch (TPGS) in comparison to thermoplastic starch (TPS) and allowed preparation of a wide range of materials by modifying the PBA/PMMA ratio in the grafted copolymer. 
a

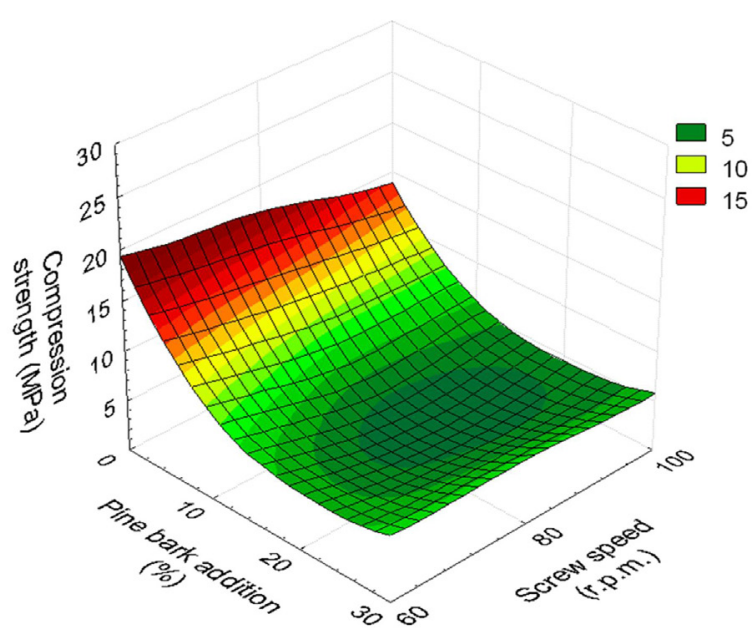

b

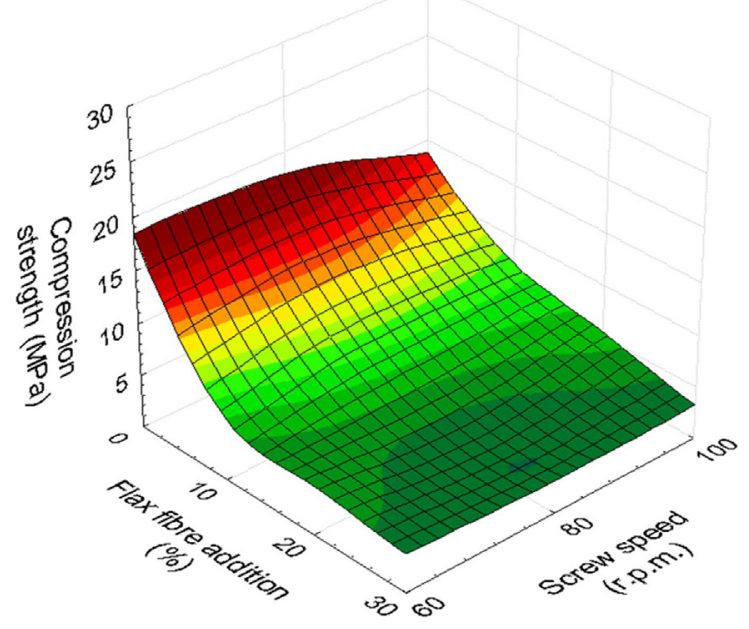

c

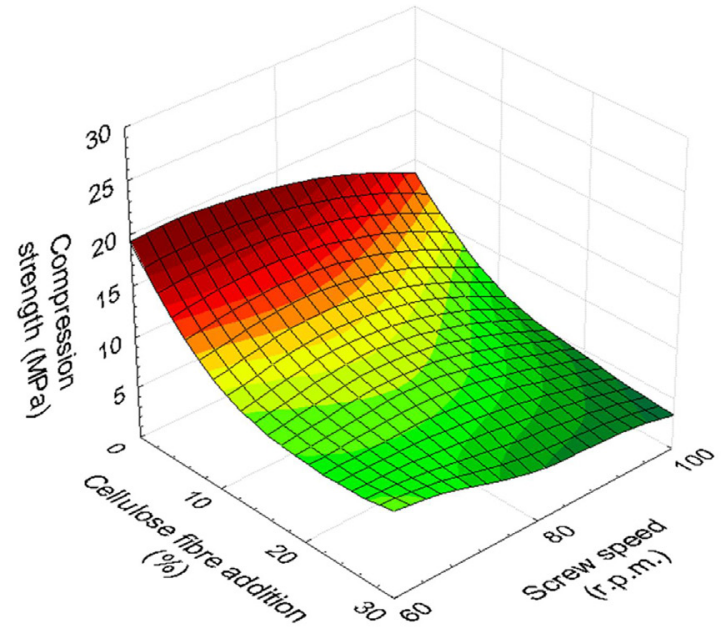

Fig. 3. Compression strength values for a different amount of: $\mathrm{a}$ - pine bark-reinforced, $\mathrm{b}$ - flax fibre-reinforced, c - cellulose fibre-reinforced granulate processed at various screw speeds during compression test.
Thermoplastic starch from ungrafted starch and grafted starch was obtained by mixing ungrafted or grafted starch with water and glycerol in a mixer camera. The TPS and TPGS with starch-g-PMMA behave as rigid materials with a high Young modulus. However, PGS with starch-g-(PBA-co-PMMA) showed less rigidity. Using dynamic mechanical analysis (DMA), an increase in the flexibility of starch due to the addition of a plasticizer was observed.

\section{CONCLUSIONS}

1. The research has shown a significant effect of the fibre addition on the mechanical properties of the thermoplastic starch. A negative influence of the fibre addition on the thermoplastic starch compression resistance was observed for all tested additives. No significant effect of the extrusion screw speed on the granulate mechanical properties was observed.

2. Among the three additives used, the best elastic modulus was observed for thermoplastic starch with a cellulose addition, and the lowest for that with flax addition. The highest value of elastic modulus, $24 \mathrm{MPa}$, was reported for $10 \%$ of cellulose addition.

3. Similar trends were observed for thermoplastic starch compression strength. The highest values of compression strength were reported for thermoplastic starch reinforced with cellulose fibre. The results varied from $18 \mathrm{MPa}$ for $10 \%$ of the additive to $7.3 \mathrm{MPa}$ for $30 \%$ of the additive.

\section{REFERENCES}

Averous L. and Boquillon N., 2004. Biocomposites based on plasticized starch: thermal and mechanical behaviours. Carbohydrate Polymers, 56, 111-122.

Camire M.E., Camire A., and Krumhar K., 1990. Chemical and nutritional changes in foods during extrusion. Food Sci. Nutrition, 29, 35-57.

Canché-Escamilla G., Canché-Canché M., Duarte-Aranda S., Cáceres-Farfán M., and Borges-Argáez R., 2011. Mechanical properties and biodegradation of thermoplastic starches obtained from grafted starches with acrylics. Carbohydrate Polymers, 86, 1501-1508.

Chen B. and Evans J., 2005. Thermoplastic starch-clay nanocomposites and their characteristics. Carbohydrate Polymers, 61, 455-463.

Cyras V., Manfredi L., Ton-That M-T., and Vázquez A., 2008. Physical and mechanical properties of thermoplastic starch/ montmorillonite nanocomposite films. Carbohydrate Polymers, 73, 55-63.

Dang K.M. and Yoksan R., 2015. Development of thermoplastic starch blown film by incorporating plasticized chitosan. Carbohydrate Polymers, 115, 575-581.

Hagenimana A., Ding X., and Fang T., 2006. Evaluation of rice flour modified by extrusion cooking. J. Cereal Sci., 43, 38-46.

Hietala M., Mathew A.P., and Oksman K., 2013. Bionanocomposites of thermoplastic starch and cellulose nanofibers manufactured using twin-screw extrusion. Eur. Polymer J., 49, 950-956. 
Huang M., Yu J., Ma X., and Peng J., 2005. High performance biodegradable thermoplastic starch-EMMT nanoplastics. Polymer, 46(9), 3157.

Huang M-F., Yu J-G., and Ma X-F., 2004. Studies on the properties of montmorillonite-reinforced thermoplastic starch composites. Polymer, 45, 7017-7023.

Matkó Sz., Toldy A., Keszei S., Anna P., Bertalan Gy., and Marosi G., 2005. Flame retardancy of biodegradable polymers and biocomposites. Polymer Degradation Stability, 88, 138-145.

Mendes J.F., Paschoalin R.T., Carmona V.B., Neto A.R.S, Marques A.C.P., Marconcini J.M., Mattoso L.H.C., Medeiros E.S., and Oliveira J.E., 2016. Biodegradable polymer blends based on corn starch and thermoplastic chitosan processed by extrusion. Carbohydrate Polymers, 137, $452-458$

Mitrus M., 2012. Starch Protective Loose-Fill Foams. In: Thermoplastic elastomers (Ed. A.Z. El-sonbati ). InTech, Rijeka, 79-95.

Mitrus M. and Mościcki L., 2009. Physical properties of thermoplastic starches. Int. Agrophys., 23, 305-308.

Moscicki L. and Janssen L.P.B.M., 2009. Thermoplastic Starch, Wiley-VCH, Weinheim, Germany.

Mościcki L., Mitrus M., Wójtowicz A., Oniszczuk T., Rejak A., and Janssen L.P.B.M., 2012. Application of extrusioncooking for processing of thermoplastic starch (TPS). Food Research Int., 47, 291.

PN-83/C-89031, 1983. Plastics. Determination of strength characteristics at static compression (in Polish).
Ray D., Sengupta S., Sengupta S.P., Mohanty A.K., and Misra M., 2007. A study of the mechanical and fracture behavior of jute-fabric-reinforced clay-modified thermoplastic starch-matrix composites. Macromolecular Materials Eng., 292, 1075-1084.

Smal T., 2009. Strength properties of repair glue composite Belzona 1111. Biuletyn WAT, LVIII, 4, 263-276.

Souza R. and Andrade C., 2002. Investigation of the gelatinization and extrusion processes of corn starch. Advanced Polymer Technol., 21(1), 17-24.

Spychaj T., Krala G., Szuniewicz A., and Pilawka R., 2008. Thermoplastic polymer blends: starch/waste polyurethane foam. In: Starch - recent progress in polymer and enzyme technology (Eds P. Tomasik, E. Bertoft, and A. Blennow). Polish Soc. Food Technol., Kraków, Poland.

Stepto R., 2003. The processing of starch as a thermoplastic. Macromolecular Symposia, 201(1), 201-212.

Suprakas S.R. and Mosoto B., 2005. Biodegradable polymers and their layered silicate nanocomposites: In greening the 21 st century materials world. Canada Research Chair on Polymer Phisics and Nanomaterials, Chemical Engineering Department, Université Laval, Sainte-Foy, Que., Canada G1K7P4.

Thomas D. and Atwell W., 1997. Starches. AACC, Minnesota, USA.

Zhang J.F. and Sun X., 2004. Mechanical properties of poly (lactic acid)/starch composites compatibilized by maleic anhydride. Biomacromolecules, 5(4), 1446-1451. 